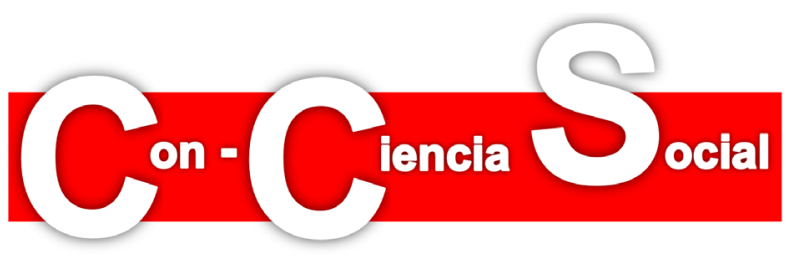

\title{
Volviendo sobre el anhelado pacto educativo en España
}

\section{Returning to the long-awaited educational pact in Spain}

\author{
F. Javier Merchán Iglesias \\ Fedicaria-Sevilla \\ jmerchan@us.es
}

Recibido en febrero de 2020

Aceptado en febrero de 2020

DOI:10.7203/con-cienciasocial.3.16793

\section{RESUMEN}

Este artículo se ocupa del Pacto Educativo en España, asunto que desde hace algunos años se plantea de manera recurrente en discursos e iniciativas políticas sobre la educación. Partiendo del estudio de las aportaciones sobre el tema recientemente publicadas por diversos autores, se analiza el origen de la cuestión en el contexto de la Transición española y de la elaboración de la Constitución. Así mismo, se considera el papel que la reciente trayectoria de la política educativa en España ha podido tener en la relevancia y significado que hoy adquiere el Pacto, así como en la posible formulación de sus términos.

Palabras clave: pacto educativo, sistema educativo, política educativa, enseñanza pública, enseñanza privada.

\begin{abstract}
This article deals with the Education Pact in Spain, an issue that has been recurrently raised in political discourses and initiatives on education for some years now. Based on the study of the contributions on the subject recently published by various authors, the origin of the issue is analysed in the context of the Spanish Transition and the drafting of the Constitution. Likewise, it considers the role that the recent development of educational policy in Spain may have played in the relevance and meaning that the Pact now acquires, as well as in the possible formulation of its terms.
\end{abstract}

Keywords: education pact, education system, education policy, public education, private education.

\section{Referencia}

Merchán, F. J. (2020). Volviendo sobre el anhelado pacto educativo en España. Con-Ciencia Social (segunda época), 3, 137-146. DOI:10.7203/con-cienciasocial.3.16793 
La reclamación de un pacto educativo en España -y también en otros países de Europa y América- se ha convertido en una demanda reiterada y hartamente proclamada por los partidos mayoritarios de nuestro sistema política -PSOE y PP-, pero también por diversas fuerzas sociales del mundo de la educación ${ }^{1}$. Ya en 2005, es decir, hace casi quince años, Mariano Rajoy, entonces líder de la oposición, ofrecía al gobierno de Zapatero un "pacto educativo". La oferta era más retórica que efectiva, pues se planteaba en el contexto del enésimo conflicto que, a propósito del rechazo de una nueva ley educativa (la LOE), planteaba la Iglesia en defensa de su privilegiada posición. Poco tiempo después, a finales de 2009, el entonces ministro de educación, Ángel Gabilondo (PSOE), impulsó sin éxito un intento de pacto educativo. El asunto se retoma en 2016 con la puesta en marcha de una subcomisión parlamentaria que, finalmente, tras varios meses de trabajo, acaba disolviéndose por la retirada de la mayoría de los grupos. En fin, la actual ministra de educación, en noviembre de 2018 , volvió a reiterar la necesidad del tan mentado pacto.

De alguna manera este es el asunto que da sustancia al núcleo principal del contenido de la obra que motiva y sirve de referencia a este artículo. Me refiero al libro coordinado por Puelles y Menor (2018) y editado recientemente por Morata. Precisamente la segunda parte de su título -Cuaderno de quejas- resulta muy expresiva del tono en el que se desenvuelven el conjunto de las aportaciones que lo conforman, es decir, el lamento de que a día de hoy no haya sido posible materializar el tan añorado pacto sobre la educación. $\mathrm{O}$, precisando algo más, que no haya sido posible consensuar el desarrollo legislativo del pacto que ya se dio justamente en la redacción del artículo 27 de la vigente Constitución española. Desde que auspiciara la formulación de la propuesta de la Fundación Encuentro (1997), Puelles ha perseguido esa tarea con empeño, quizás sin caer en la cuenta de que precisamente aquella redacción, junto con los Acuerdos firmados en 1979 entre el estado español y el Vaticano -todavía vigentes-, delimitaron un estricto campo de actuación que acabó por cerrarse con la aprobación y promulgación de la Ley Orgánica del Derecho a la Educación (LODE, 1985), presentada a las Cortes por el entonces gobierno del PSOE.

La estructura y contenido de la obra que comentamos es ciertamente sugerente, si bien la introducción y el epílogo, firmados por sus coordinadores,

\footnotetext{
${ }^{1}$ La cuestión del Pacto Educativo fue motivo central del editorial del número uno (segunda época) de esta misma revista (Editorial, 2018).
} 
resultan en muchos puntos contradictorios con alguna de las colaboraciones. Es posible que tampoco se haya pretendido la homogeneidad en las aportaciones del nutrido elenco de autores, si bien su variada procedencia intelectual y, sobre todo, profesional, obstaculiza la loable pretensión de ofrecer una mirada poliédrica sobre el mismo tema. El texto se articula con una introducción que quiere ser la presentación o hipótesis sobre el problema, un epílogo que actuaría como conclusión y dos partes en las que, a modo de aparato empírico, se aportan los argumentos de la tesis que se defiende. No obstante, sin menoscabo de su interés y calidad, el recorrido termina resultando algo artificioso, pues desde el principio de la obra el lector o lectora ya puede conocer la conclusión, lo que le confiere al libro un carácter menos analítico.

La primera parte aborda una aproximación histórica al principal problema de la educación en España, que no es otro que el conflicto que enfrenta al Estado y la Iglesia católica por el control sistema educativo y su poder en la formación de las conciencias. Aquí Antonio Viñao documenta con la solvencia que caracteriza sus trabajos cómo el mentado problema se remonta al proceso de configuración del sistema educativo nacional a lo largo del siglo XIX. En sus orígenes el conflicto en cuestión enfrenta al liberalismo consigo mismo, pero, pronto, es la Iglesia la que toma la bandera de la defensa de la enseñanza privada, ganando posiciones frente a la tesis de un sistema educativo gestionado fundamentalmente por el Estado. Por su parte, continuando con el recorrido histórico, la aportación de Emilio Castillejo desgrana la consagración de ese poder eclesiástico a lo largo de la dictadura franquista, período en el que la enseñanza pública devino en un elemento meramente asistencial, subsidiario de la privada. Esta es la realidad con la que se topa la Transición y con la que hubo que abordar la reformulación del sistema educativo en el venidero contexto de la democracia parlamentaria. Como nos dice Antonio Baylos en su aportación, la posición de la derecha -que el autor atribuye meramente a Alianza Popular (AP), pero que representó con más fuerza la Unión de Centro Democrático (UCD) - se sustanciaba en la defensa de los postulados e intereses de la Iglesia en materia educativa, es decir, de la situación heredada del franquismo, admitiendo, si acaso, una mayor dignificación de la enseñanza pública. En lo que hace al papel del PSOE -asunto al que el autor apenas hace referencia-, su posición fue variando en pocos meses, desde la defensa del modelo de escuela 
pública de la II República ${ }^{2}$ hasta la asunción del consenso antes aludido que, como se ha dicho, consagraba la estructura dual del sistema educativo y el relevante papel de la Iglesia.

La calculada ambigüedad con la que resultó finalmente la redacción del artículo 27 es signo evidente de aquel consenso que, de manera más o menos explícita, dejaba abierta la puerta a un posterior desarrollo legislativo favorable a las posiciones que venía manteniendo la derecha. Pero la descomposición de la UCD y el consiguiente descarrilamiento de sus tesis sobre la configuración del sistema educativo de la democracia paralizaron momentáneamente sus planes. Fue precisamente el PSOE, con la aprobación, en 1985, de la LODE -junto al mantenimiento de los citados acuerdos con la Santa Sede- quien definitivamente les dio carta de naturaleza. A este respecto, las aportaciones de Alejandro Tiana y Mario Bedera, que han ocupado cargos importantes en el Ministerio de Educación de gobiernos del PSOE, tienen un sesgo algo partidista, pues en el análisis histórico del desarrollo legislativo posterior, obvian la existencia del pacto educativo de la Transición, reprochando a los sucesivos gobiernos del Partido Popular -heredero de la política educativa de la UCD- su deriva cada vez más consistente hacia la privatización del sistema educativo. Pero el caso es que de eso ya estábamos advertidos, pues en aquel pacto se contenía el germen de lo que habría de venir y quedaba claro que ese consenso les facultaba para ello. También, aunque menos, para lo contrario, es decir, para el fortalecimiento de la enseñanza pública, si bien poco o nada se ha venido haciendo en este sentido.

En esas aportaciones se desgranan las distintas leyes que se promulgan entre 1982 y 2015, es decir, desde la LOGSE (1990) hasta la vigente LOMCE (2013), dando cuenta de las sucesivas reformas y contrarreformas que se suceden hasta nuestros días. Precisamente este carrusel legislativo es la munición más empleada en la divulgación de la necesidad de un pacto educativo. Así, da la impresión de que el Pacto se convierte en un bien en sí mismo, hasta el punto de que el contenido del hipotético acuerdo de estado puede terminar siendo secundario, con tal de que se ponga fin a la agotadora proliferación legislativa que emana de los distintos gobiernos y que inunda recurrentemente las páginas del Boletín Oficial del Estado con leyes que se pretenden soluciones verdaderas y definitivas.

\footnotetext{
${ }^{2}$ La actualización de ese modelo se concretó entonces en la que se llamó Alternativa democrática para la enseñanza, documento aprobado por el Colegio de Doctores y Licenciados de Madrid.
} 
La segunda parte del libro coordinado por Puelles y Menor da voz a la comunidad educativa, recogiendo aportaciones de estudiantes, familias y profesorado acerca de la aplicación del artículo 27 de la Constitución. Alejando Delgado Rivero, presidente de la Federación de Estudiantes Progresistas de España (FAEST) -considerada afín al PSOE-, nos presenta un texto con un tono marcadamente reivindicativo. Desglosa en sus páginas toda la serie de problemas que aquejan a los estudiantes y que han dado pie a las históricas luchas del movimiento estudiantil desde la dictadura hasta nuestros días. Una colección de temas y episodios que adolecen de cierta profundidad analítica. Abundando en una de las ideas fuertes que nos quiere trasladar el conjunto del libro, el mismo título de su escrito, "El alumnado en el eterno anhelo del cumplimiento del artículo 27", es suficientemente revelador. Efectivamente, con una estructura poco cuidada y unos argumentos escasamente consistentes, el autor nos sugiere que, si realmente se cumpliera lo dispuesto en el citado artículo, las cosas de la educación en España irían de otra manera, mucho mejor. Semejante ingenuidad nos permite apreciar que, mientras la derecha tiene claro un proyecto para la educación, en el lado del denominado progresismo se añora meramente una vuelta al consenso de la Transición. Un consenso que el denominado movimiento progresista entiende fracturado por la agresiva política de las fuerzas conservadoras, a las que, sin mirarse a sí mismo, hacen únicas responsables de la fractura. Así que, a la vista del aguacero que está cayendo, sólo quedaría apelar al pacto para minimizar al menos los efectos de esa política.

La voz de las familias es traída a colación por José Luis Pazos Jiménez, miembro destacado del movimiento de Madres y Padres del alumnado, habiendo presidido la FAPA Giner de los Ríos de Madrid, así como la CEAPA (Confederación Estatal). La aportación de Pazos es quizás la más crítica de las que se nos presentan en el conjunto del libro. Su planteamiento no cuestiona la vigencia del renombrado artículo 27 de la Constitución, pero sostiene con notables argumentos que con ese mismo texto se puede hacer otra política educativa muy distinta que la que unos y otros han fraguado hasta ahora. Su consideración se fundamenta en la tesis de que hasta ahora ha predominado una lectura conservadora, transmitiéndose mensajes que han desvirtuado el significado del citado artículo. Asumiendo que su ambigua redacción es en sí misma un pacto, en el posterior desarrollo e interpretación ha primado la debilidad de la izquierda y la fortaleza de la derecha. En 
consecuencia, si hoy no parece posible una nueva redacción -opción que, en todo caso, no habría que descartar-, sí es viable otra interpretación que acometa una decidida defensa de la escuela pública. El autor desgrana su argumento mediante un detallado y documentado análisis de cada uno de los apartados del artículo 27. Así, sostiene que el derecho a la educación no se agota con la mera escolarización, es decir, sólo con el alojamiento del alumnado durante algunas horas en los centros escolares. Educación es algo más que escolarización. Por otra parte, nos propone profundizar en el objeto de la educación señalado en el texto constitucional -el pleno desarrollo de la personalidad humana...- y en las consecuencias prácticas que de ello se derivan. Argumenta también que, cuando el texto constitucional garantiza el derecho de los padres a que los hijos reciban la formación religiosa y moral que esté de acuerdo con sus convicciones, ello no implica que tal formación haya de procurarse en la escuela ni con cargo a fondos públicos. Por lo demás, la libertad de creación de centros docentes no avala que el estado haya de financiarlos. $Y$, en fin, en este mismo sentido, considera que el polémico apartado 9 -"Los poderes públicos ayudarán a los centros docentes que reúnan los requisitos que la ley establezca" - no implica que esa ayuda deba consistir en la financiación pública de los centros privados, una consideración que se apoya en el fundamento jurídico $3^{\circ}$ de la sentencia del Tribunal Constitucional 86/1985.

En definitiva, el capítulo firmado por José Luis Pazos estaría en la línea de lo que defendieron algunos dirigentes del PSOE en el debate educativo de la Transición, aceptar la escuela privada, si bien con el propósito de promover la enseñanza pública: "Es decir, se mantendría el número de centros privados y se los diluiría en un crecimiento masivo de la enseñanza estatal" (González-Moreno, 2019, p. 5).

El análisis de la perspectiva del profesorado sobre la aplicación del artículo 27 de la Constitución española nos viene de la pluma de María Pérez-Ugena Coro y de Carmen Perona Mata, ambas provenientes del campo del Derecho y de los estudios sobre Administración Pública. Quizás sea por esa circunstancia que su aportación resulta algo disonante en el conjunto de la obra, pues, a decir verdad, no aporta mucho en relación con el asunto del que se trata. Si bien se hacen algunas consideraciones sobre la participación del profesorado en el sistema educativo, se hubiera agradecido un estudio algo más específico. 
El epílogo de nuestro libro corre a cargo de Puelles. Resumidamente allí se da cuenta de las aportaciones de los distintos autores para concluir enlazando con la introducción de Menor. Un texto que adolece de cierto eclecticismo en el intento de hilvanar, a veces forzadamente, las distintas aportaciones. Con todo, el autor aboga por un nuevo consenso que pasaría por una revisión del artículo 27 o, al menos, por una nueva ley educativa que renueve el pacto de la Transición, perfilando claramente los aspectos más controvertidos de ese artículo. Un loable deseo que en última instancia es el que justifica la obra comentada.

Como decía al principio de este artículo, la cuestión del pacto educativo en España se ha convertido en un tópico y en una suerte de reclamo que, amparándose en las supuestas virtudes del consenso y en la denostada recurrencia a ley por gobierno, busca legitimidad ante la opinión pública para terminar aplicando la política educativa que ya se ha decidido aplicar. Si examinamos el asunto con detalle, veríamos que en realidad se dan vueltas sobre el conflicto planteado en la Transición, sin que unos y otros asuman cabalmente el resultado de lo que entonces se pactó. Efectivamente, recordemos que el nudo gordiano de aquel conflicto fue el estatus de la enseñanza privada y, particularmente, de la Iglesia en el sistema educativo español. Desde la perspectiva de la izquierda el acuerdo consistió en asumir el statu quo heredado del franquismo, es decir, el control por parte de la Iglesia de en torno a un treinta por ciento de centros escolares, a cambio de los recursos necesarios para mantener un sistema público mínimamente aceptable.

En opinión de la formación socialista, se había conseguido con la redacción del artículo 28 sentar las bases de un "pacto escolar" reflejando en aquel texto un mínimo razonable de aspiraciones tanto de unos como de otros. Así, en el precepto indicado se veían reflejados aspectos importantes como el reconocimiento del derecho a la educación, el carácter obligatorio y gratuito de la enseñanza básica, la participación de la comunidad educativa en los centros; de otra parte, la libertad de enseñanza invocada por la formación de centroderecha se veía reflejada en el reconocimiento a la libertad de creación de centros docentes, la percepción de ayudas a los mismos o el derecho que asistía a los padres para que eligiesen la educación religiosa y moral que estuviese más de acuerdo con sus propias convicciones. (Hernández Beltrán, 2008, pp. 39-40) 
Mientras que con esta posición el PSOE renunciaba a su modelo de educación basado en la escuela pública, quizás no se apreciaba entonces que la derecha no interpretaba la situación de la misma forma. Entendiendo "la educación como un hecho radicalmente privado, que debía ser gobernado institucionalmente por la familia y la Iglesia" (Baylos, 2018, p. 85), concebía -y concibe- el papel del Estado como meramente subsidiario de las familias, de manera que son estas las que deben determinar el tipo de formación -y, por tanto, de escuela- que quieren paras sus hijos e hijas, correspondiendo al Estado meramente apoyar financieramente esta decisión. Se trataba de una posición a la que no parecían dispuestos a renunciar; de hecho, Oscar Alzaga, portavoz de la Unión de Centro Democrático, anunciaba en aquellas fechas que su grupo iba a trabajar insistentemente en el Parlamento para aplicar en la ley su programa educativo (Sevilla Merino, 2016). Y así lo hicieron.

Ya en junio de 1978, el gobierno de la UCD aprobó el Proyecto de Ley Orgánica por la que se regula el Estatuto de Centros Escolares (LOECE), proyecto que concedía un estatus independiente a los centros privados que estuvieran subvencionados públicamente. De manera complementaria, en septiembre de ese mismo año, aprobó también un Proyecto de Ley de Financiación de la Enseñanza Obligatoria en el que se adoptaba la fórmula del cheque escolar que se aplicaría indistintamente para la estatal y la privada, al margen del ideario que esta tuviera. En enero de 1979, es decir, pocos días después de aprobarse la Constitución, se firmó el Acuerdo entre el Estado Español y la Santa Sede sobre enseñanza y asuntos culturales, un acuerdo todavía vigente que actualizaba el Concordato de 1953 con el Vaticano. En este acuerdo no sólo se garantizaba la presencia de la enseñanza de la Religión en los centros escolares estatales, sino que, en su artículo XIII, se incluía expresamente a los centros de la Iglesia católica en cualquier régimen de subvención. En fin, en agosto de 1980 se aprobó un decreto-ley que concedía una "multimillonaria ayuda a la enseñanza privada" (Hernández Beltrán, 2008, p. 77).

Dado que esta política acabó descarrilando, bien por sentencias del Tribunal Constitucional, bien por la descomposición de la UCD, el PSOE aprobó la LODE (1985), ley en la que, como se ha dicho anteriormente, se naturalizaba la subvención pública a la enseñanza privada, suponiendo que, de esta forma se daría por cerrado el pacto educativo de la Transición. Sin embargo, la derecha ha seguido pugnando por implantar su modelo educativo mediante la aprobación de nuevas leyes como la LOCE (2002) o la actualmente vigente, la LOMCE (2013). 
Así pues, a la vista de la irreductible posición de la derecha en aras de aplicar su programa sobre educación, podemos pensar que el constante llamamiento a un pacto educativo pudiera entenderse también como el deseo de retomar el acuerdo de la Transición, constantemente vulnerado y reinterpretado por las fuerzas conservadoras, pues, según Puelles (2002), el pacto sobre la educación supuso el consenso básico (aceptación de la igualdad, la libertad y la participación) pero evitó imponer el consenso político que hubiera obligado a todos los partidos a promover las mismas políticas (Sevilla Merino, 2016, pp. 56-57).

\section{REFERENCIA PRINCIPAL}

Puelles, M. de y Menor, M. (coords.) (2018). El artículo 27 de la Constitución. Cuaderno de quejas. Madrid: Morata.

\section{REFERENCIAS}

Baylos, A. (2018). El marco constitucional del derecho a la educación: Debates y proyectos en el período constituyente. En Puelles, M. y Menor, M. (coords.), El artículo 27 de la Constitución. Cuaderno de quejas (pp. 77-97). Madrid: Morata.

Editorial (2018). Con-Ciencia Social (segunda época), 1, 5-17. Recuperado de https://bb7960e1-26dd-4e9b-8afc-861b4bc81988.filesusr.com/ugd/61fdc1_ 9f0ec57675724e2b930893b07de88ddd.pdf

González-Moreno, J. (2019). Política, ideología y educación en el PSOE durante la Transición (1976-1982): Escolarización y secularización. Archivos Analíticos de Políticas Educativas, 27(108). DOI: https://doi.org/10.14507/epaa.27.4042

Fundación Encuentro (1997). Declaración conjunta en favor de la educación. Madrid. Recuperado de https://www.fund-encuentro.org/fundacion_php/cuadernos/ varios/Declaracion\%20conjunta.pdf

Hernández Beltrán, J. C. (2008). Política y educación en la transición democrática española. Foro de Educación, 10, 57-92.

Puelles, M. de (2002). El pacto escolar constituyente: génesis, significación y situación actual. Historia de la Educación, 21, 49-66.

Sevilla Merino, D. (2016). La difícil traslación a una política de gobierno de un acuerdo constitucional forzado. La Unión de Centro Democrático y su malograda Ley Orgánica de Estatuto de Centros Escolares (LOECE) de 1980. Historia y Memoria de la Educación, 3, 45-70. 
